\title{
Improved expression by cytomegalovirus promoter/enhancer and behavior of vascular endothelial growth factor gene after myocardial injection of naked DNA
}

\author{
Jin Ok Jeong ${ }^{1}$, Jonghoe Byun ${ }^{2}$, Eun-Seok \\ Jeon', Hyeon-Cheol Gwon', Young Shin Lim², \\ Jangwon Park' ${ }^{2}$, Seon-Ju Yeo², Young Joo \\ $\mathrm{Lee}^{3}$, Sunyoung $\mathrm{Kim}^{4}$ and Duk-Kyung $\mathrm{Kim}^{2,5}$ \\ ${ }^{1}$ Department of Internal Medicine, Chungnam National University \\ School of Medicine, Daejeon 301-721, Korea \\ ${ }^{2}$ Department of Medicine, Sungkyunkwan University School of \\ Medicine, Samsung Medical Center, Laboratory of Cardiovascular \\ Molecular Therapy, MTRC and SBRI, Seoul 135-710, Korea \\ ${ }^{3}$ Department of Bioscience, Sejong University, Seoul 143-747, \\ Korea \\ ${ }^{4}$ Institute of Molecular Biology and Genetics, Seoul National Univer- \\ sity, Seoul 151-742, Korea \\ ${ }^{5}$ Corresponding author: Tel, 82-2-3410-3413; \\ FAX, 82-2-3410-3417; E-mail, dkkim@ smc.samsung.co.kr
}

Accepted 29 July 2002

Abbreviations: VEGF, vascular endothelial growth factor; HCMV IE, human cytomegalovirus immediate early; CAT, chloramphenicol acetyl transferase; LTR, long terminal repeat; RSV, Rous sarcoma virus; EF-1 $\alpha$, elongation factor- $1 \alpha$

\begin{abstract}
Direct injection of the vascular endothelial growth factor (VEGF) gene plasmid DNA into the myocardium was shown to induce development of new blood vessels to increase the circulation in the heart of patients with coronary artery diseases. However, such angiogenic gene therapy (via naked DNA) was limited by low level of gene expression. Furthermore, the temporal and spatial characteristics of VEGF gene transfer in the heart are not known. In this study, we demonstrated that a plasmid vector, containing the human cytomegalovirus immediate early (HCMV IE) promoter and enhancer, induces greater expression of gene in the rat heart monitored by gene fused to the chloramphenicol acetyl transferase (CAT) reporter, than four different viral and cellular promoters. Interestingly, expression of VEGF $_{121}$ protein showed an earlier peak, a shorter duration, and a wider distribution than that of CAT only. Therefore, a plasmid vector with an HCMV IE promoter/enhancer provides clear advantages over other previously developed plasmids. Furthermore,
\end{abstract}

expression profile of VEGF $_{121}$ gene may provide useful information in the design of angiogenic gene therapy in the heart.

Keywords: naked DNA, gene therapy, VEGF, heart

\section{Introduction}

Angiogenic gene therapy to promote the development of supplemental collateral blood vessels in chronic myocardial ischemia has been exploited using direct myocardial administration of the vascular endothelial growth factor (VEGF) gene, in the form of naked DNA (Rosengart et al., 1999). Preliminary results using this strategy suggest that it may constitute an alternative treatment for patients with severe myocardial ischemia (Losordo et al., 1998; Symes et al., 1999) and heart failure (Carmeliet et al., 1999; Isner et al., 1999).

The success of gene therapy depends largely on the efficacy of gene delivery vectors. Although naked DNA is probably the safest and the most convenient form of gene delivery vector, its application has been limited by the attendant low level of gene expression (Verma et al., 1997). A potent eukaryotic expression vector will not only increase the efficacy and success of angiogenic gene therapy, but will also decrease the cost of therapeutic vectors in clinical application. Strategies to improve the efficiency of non-viral vectors include the development of enhanced expression plasmids. Enhancement of gene expression from plasmids might be achieved by altering the regulation of gene expression from the plasmid (Lee et al., 2000). Accordingly, we sought to investigate the potency, following direct injection into the myocardium, of vectors with different viral and cellular promoters.

Despite significant use of the VEGF gene injected as naked DNA into the patients heart (Losordo et al., 1998; Symes et al., 1999), the kinetics and distribution of VEGF protein after plasmid injection in the heart have not yet been defined. In previous reports, several laboratories have demonstrated the expression of naked DNA injected into the animal heart (Lin et al., 1990; Kitsis et al., 1991; Buttrick et al., 1992; von Harsdorf et al., 1993; Li et al., 1997). In these experiments, use was made of reporter genes, such as chloramphenicol acetyl transferase (CAT), $\beta$-galactosidase, or luciferase, which encode intracellular proteins with long half-lives. Following direct injection of naked DNA into animal hearts, these studies reported cases of long-term 
expression, restricted to the area surrounding the needle injection site. However, these results do not permit any conclusions about the behavior of the VEGF gene, which is known to have a half-life of only a few minutes, and which encodes a signal sequence that facilitates secretion of the protein from intact cells (Ferrara et al., 1992). Indeed, these facts suggest that VEGF might differ substantially in both its kinetics and its tissue distribution from proteins encoded by reporter genes.

Moreover, the VEGF transcript is normally spliced into at least five different forms (Neufeld et al., 1999). Different isoforms of VEGF protein show different binding affinities for heparan sulfate, a component of the extracellular matrix. Of these, the isoform VEGF VI21 $_{1}$ binds least well to heparin, and diffuses into the systemic circulation (Park et al., 1993). Therefore, investigation is required into the specific behavior, in terms of kinetics and spatial distribution, that characterizes $V_{E G F} F_{121}$ in the heart after gene delivery.

The first aim of the present study was to examine the relative potency of eukaryotic expression vectors, with different promoters, in the myocardium after direct injection into the heart. The second aim was to investigate the behavior of VEGF ${ }_{121}$ after direct naked DNA injection into the rat heart, and to compare this with the behavior of the CAT reporter gene product.

\section{Materials and Methods}

\section{Structure of expression vectors}

For the comparison of promoter potency, five plasmids were used in this study (Figure 1A). Plasmid pcDNA3.1 was purchased from Invitrogen and contains 587 base pairs (bp) of HCMV IE promoter. Plasmid pRSV contains the enhancer and promoter region of the $3^{\prime}$ long terminal repeat (LTR) of the Rous sarcoma virus (RSV). We have constructed pCN, pEF1- $\alpha$, and pAct. For plasmids $p C N, p E F 1-\alpha$, and $p A c t$, the promoter region of pcDNA3.1 was replaced with each promoter, thereby making the backbone of each identical to pcDNA3.1. The construction and structures of $\mathrm{pCN}$, pEF1- $\alpha$, and pAct have been described elsewhere (Lee et al., 2000). Briefly, pCN contains the 600 bp HCMV IE promoter and its entire $5^{\prime}$ untranslated region, consisting of $122 \mathrm{bp}$ of exon 1, $827 \mathrm{bp}$ of intron 1, and $16 \mathrm{bp}$ of exon 2. Plasmid pEF contains $137 \mathrm{bp}$ of the human elongation factor-1 $\alpha(E F-1 \alpha)$ promoter and its entire $5^{\prime}$ untranslated region, consisting of $20 \mathrm{bp}$ of exon 1, 945 bp of intron 1, and 31 bp of exon 2. Plasmid pAct contains $243 \mathrm{bp}$ of human $\beta$-actin promoter and its entire $5^{\prime}$ untranslated region, consisting of 76 bp of exon 1, 696 bp of intron 1, and 87 bp of exon 2. In both CAT and human VEGF $_{121}$, the ATG codon was positioned at the site of the original start codons of the respective genes. The cDNA encoding human $V E_{121}$ was cloned from total RNA prepared from human placenta by RT-PCR. The primers used were 5 '-ATGAACTTTCTGCTGTCT-3' (sense) and 5'-TCACCGCCTCGGCTTGT CACATTTTTC-3' (antisense). The amplified CDNA was subcloned into the pCR2.1 vector (Invitrogen), and was confirmed by sequencing. Bioactivity of human VEGF $F_{121}$ was confirmed by the Mile's permeability assay (Darren et al., 2001).

\section{DNA preparation}

Plasmids were prepared using the column method (Plasmid MegaKit; Qiagen, CA). All plasmid preparations contained a high percentage of supercoiled DNA (70$80 \%$ ), and no RNA was detectable by gel electrophoresis. For injection, DNA was dissolved in $50 \mu \mathrm{l}$ of normal saline.

\section{Animal experiments}

All animal experiments were carried out in conform with the Guideline for the Care and Use of Laboratory Animals published by the US National Institute of Health (NIH Publication No. 85-23, revised 1996). Male SpragueDawley rats weighing 300 grams were used for naked DNA injection. The rats were anesthetized with intraperitoneal ketamine-xylazine $(50 \mathrm{mg} / \mathrm{kg}$ and $2 \mathrm{mg} / \mathrm{kg}$, respectively), intubated, and mechanically ventilated with room air. Under aseptic conditions, a thoracotomy was performed through the left fifth intercostal space, and the heart was exposed. Cardiac injections were made directly into the apex of the left ventricle. Fifty microliters of a DNA solution containing each plasmid were injected into the apical portion of the beating left ventricle, under direct visualization, using a 29-gauge needle. The DNA injection caused immediate subepi-cardial edema, with the tissue changing color from red to pink. The chest was then closed, and the animals were allowed to recover for specific periods before sacrifice. An antibiotic ( $0.1 \mathrm{~g}$ cefazolin) was injected intramu-scularly on the day of cardiac injection.

\section{Measurement of CAT and VEGF}

Rats were killed at the indicated times following cardiac injection. The atria and great vessels were trimmed, and the hearts were washed in ice-cold phosphate-buffered saline. Except when indicated, the apical one third of the heart was homogenized in $2 \mathrm{ml}$ ice-cold homogenization buffer (25 mM Tris- $\mathrm{HCl}, \mathrm{pH} 7.4,50 \mathrm{mM} \mathrm{NaCl}, 0.5 \% \mathrm{Na}-$ deoxycholate, $2 \%$ NP-40, $0.2 \%$ sodium dodecyl sulfate, $1 \mathrm{mM}$ PMSF). Homogenates were then centrifuged at $6,000 \mathrm{~g}$ for $10 \mathrm{~min}$ at $4^{\circ} \mathrm{C}$. Supernatants were collected to measure the levels of CAT and human VEGF, using commercially available ELISA kits (CAT, Boehringer Mannheim, Switzerland; VEGF, R\&D Systems, MN). Compared to the classical ${ }^{14} \mathrm{C}$-based CAT assay, the 
A

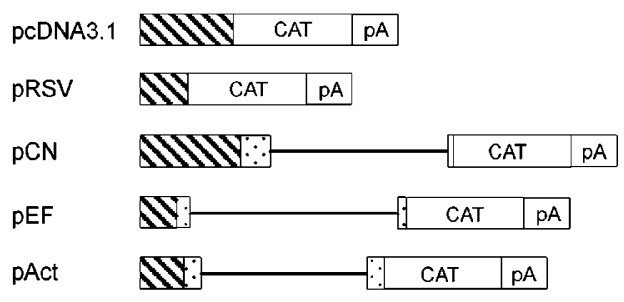

B

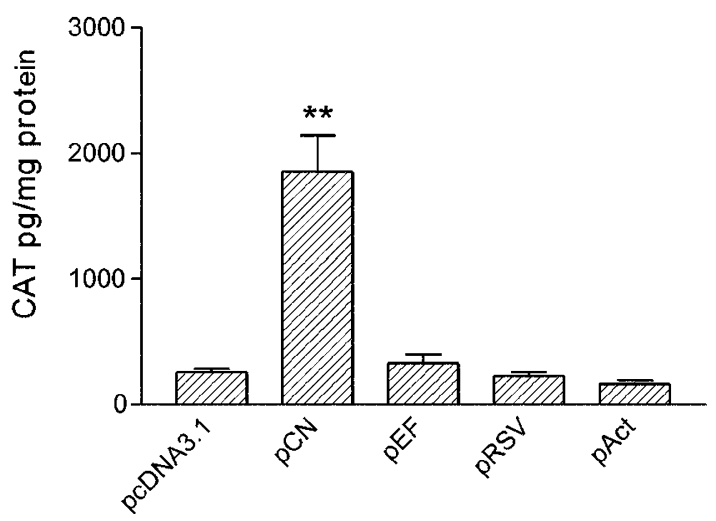

Figure 1. (A) Structure of expression vectors. Hatched box, promoter; dotted box, exon; line, intron; pA, polyA tail. (B) Comparison of the levels of gene expression of the five promoters coupled to the chloramphenicol acetyl transferase (CAT) gene. Thirty micrograms of DNA were injected into rat hearts in vivo. Three days after injection, rats were sacrificed, and their hearts assayed for CAT expression by ELISA. ${ }^{\star \star} P<0.01$ vs. other promoters. Values are given as mean \pm SEM (n varies from 8 to 15 for each promoter).

CAT ELISA provides more accurate measurements for the actual amount of CAT protein synthesized, rather than merely measuring the CAT enzyme activity, which can decrease during long-term storage. The CAT ELISA also allows direct comparison of data from different sets of experiments, and is equal in sensitivity to the radioactive CAT assay. The VEGF ELISA kit is specific to human VEGF. Antibody used in the kit has no cross reactivity against murine VEGF. Protein was quantified using a calorimetric assay (Bio-Rad, CA). Results are expressed as picograms of CAT or VEGF per milligram protein \pm standard error of the mean (SEM).

\section{Statistics}

Results are expressed as the mean \pm standard error of the mean (SEM). The means of groups were compared by an unpaired two-tailed Student's $t$-test. Statistical significance was assumed if the null hypothesis could be rejected at the 0.05 level.

\section{Results}

\section{Comparison of in vivo gene expression in the rat heart using different promoters}

Initially, we determined the relative strength of five promoters linked to the CAT reporter gene. In these experiments, $30 \mu \mathrm{g}$ each of pcDNA3.1-CAT, pCN-CAT, pEF-CAT, pRSV-CAT, or pAct-CAT was injected into the apex of the rat heart. The rats were killed three days after injection, and levels of CAT gene expression were analyzed by ELISA. The data, which are shown in Figure $1 \mathrm{~B}$, demonstrate that $\mathrm{pCN}$ was about sevenfold more greater than those expressed with other promoters $(P<0.05)$. The ranking of potency of gene expression was $\mathrm{pCN}>>\mathrm{pEF}>\mathrm{pcDNA3.1}>\mathrm{pRSV}>\mathrm{pAct}$. However, apart from $\mathrm{pCN}$, there was no significant difference in gene expression between viral (pRSV, pcDNA3.1) or cellular (pEF, pAct) promoters.

\section{Expression of pCN-CAT injected into the myo- cardium}

To determine the dose-response of CAT gene expression after direct intracardiac injection, increasing doses of naked DNA in $50 \mu \mathrm{l}$ saline were injected into the heart. Proteins were extracted from the injected heart three days later, and levels of CAT were determined. As depicted in Figure 2A, an injected amount as small as $1 \mu \mathrm{g}$ DNA resulted in significant CAT expression. CAT expression increased in a dose-responsive manner in the range of 1-10 $\mu \mathrm{g}$ DNA, before reaching a plateau at doses over $10 \mu \mathrm{g}$, reflecting saturation kinetics in DNA uptake, transcription, or both. Injection of even higher amounts of total DNA resulted in a decrease in the expression of CAT $(P<0.05$ compared to the peak level of CAT gene expression). The reasons for this reaction is not known at this time. However, we conjecture that high levels of foreign bacterial protein might interfere with transcription, with translation, or with both.

We have also tested the time course of CAT gene expression after direct intracardiac injection. The rats were injected with $10 \mu \mathrm{g}$ of pCN-CAT, and then killed at various intervals; data are plotted in Figure 2B. CAT expression was detectable one day after injection, with a peak at day five, and a subsequent decline in expression through to day 30 . Significant levels of CAT were detectable even 30 days after a single injection.

\section{Expression of pCN-VEGF ${ }_{121}$ injected into the myo-} cardium 
A

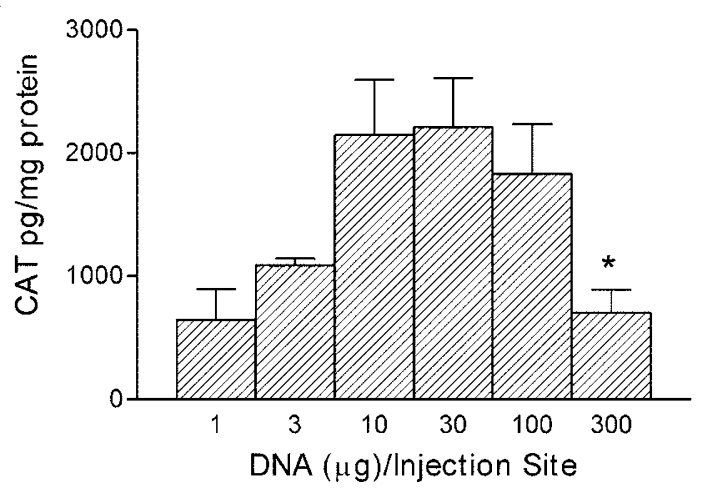

B

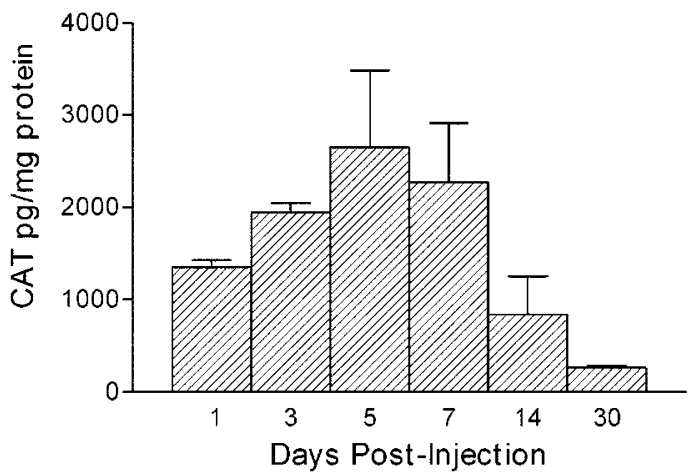

Figure 2. Bar graphs showing dose-response data and time-course of the expression of injected pCN-CAT. (A) Different concentrations of DNA were injected in $50 \mu \mathrm{l}$ normal saline (NS). Three days after injection, hearts were excised and levels of CAT protein were determined by ELISA. ${ }^{*} P<0.05$ compared to the value for $30 \mu \mathrm{g}$. Values are given as mean \pm SEM ( $n=3$ for each dose). (B) Ten micrograms of plasmid were injected into the rat heart, and the heart assayed for CAT by ELISA at each time point. Values are given as mean \pm SEM ( $n=3$ for each time point).

A

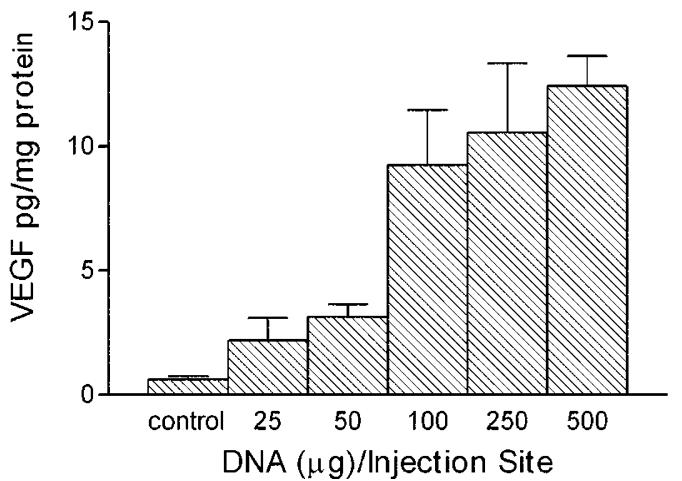

B

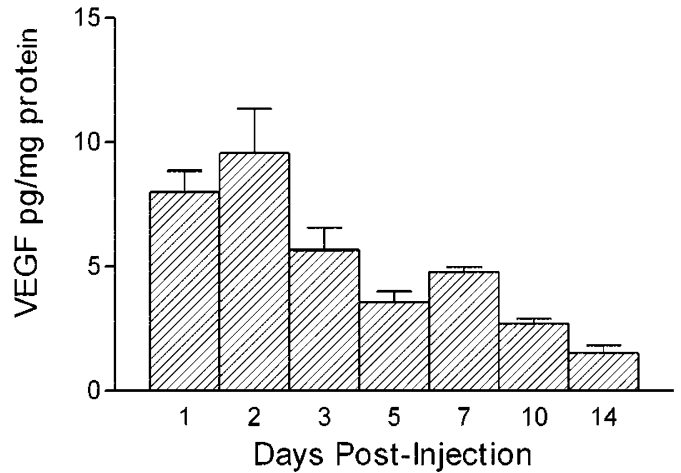

Figure 3. Dose-response and time-course of the expression of injected pCN-VEGF 121 . (A) Different concentrations of DNA were injected in $50 \mu l$ saline. Two days after injection, hearts were excised and levels of VEGF protein were determined. pCN-CAT was used as a control. Values are given as mean \pm SEM $(n$ $=3$ for each dose). (B) Two hundred fifty micrograms of plasmid were injected into the rat heart, and the hearts were assayed for VEGF using ELISA at each time point. Values are given as mean $\pm \operatorname{SEM}(n=3$ for each time point).

To determine the efficiency and kinetics of expression of the VEGF gene injected into rat myocardium, we injected a constant volume of $50 \mu \mathrm{l}$ containing an increasing amount of $p C N-V E_{121}$ plasmid DNA, ranging from 25 $500 \mu \mathrm{g}$ per injection site, into each rat heart. The rats were killed two days after injection, proteins were extracted from the heart, and the level of VEGF gene expression was analyzed by ELISA. The data shown in Figure $3 \mathrm{~A}$ indicate that, contrary to the pattern of expression of the CAT gene, there was a linear dose-response relationship between the level of VEGF gene expression and the quantity of plasmid DNA injected between 25 and $500 \mu \mathrm{g}$ per injection site.

To examine the duration of expression from the VEGF $_{121}$ gene delivered as naked DNA, we injected a single dose of $250 \mu \mathrm{g}$ of DNA into the heart and analyzed by ELISA the level of VEGF produced for the next 14 days (Figure 3B). Peak VEGF 121 expression occurred two days after injection, and then slowly declined. Significant levels of VEGF were detectable even 14 days after the single injection.

\section{Spatial extent of expression of VEGF at the protein level in cardiac muscle}

To determine the spatial extent of expression of injected genes in the heart, we injected the apical portions of individual hearts with a single $50 \mu$ bolus of pCN-CAT $(30 \mu \mathrm{g})$, or pCN-VEGF ${ }_{121}(250 \mu \mathrm{g})$. After injection of each DNA construct, the rats were killed on the day of peak expression. The hearts were cut into four sections from apex to base, and these sections were then assayed individually for the presence of protein, using ELISA. Data are shown in Figure 4. The relative amount of protein extracted from each section showed quite striking differences between the two genes. Over $99 \%$ of the expression of the CAT gene was restricted exclusively to the apical section that included the injection site (Figure 4A). As described in Figure 4B, the level of VEGF ${ }_{121}$ protein showed a concentration gradient from the apex to the base, i.e., $44 \%$ VEGF protein in the apical section, 


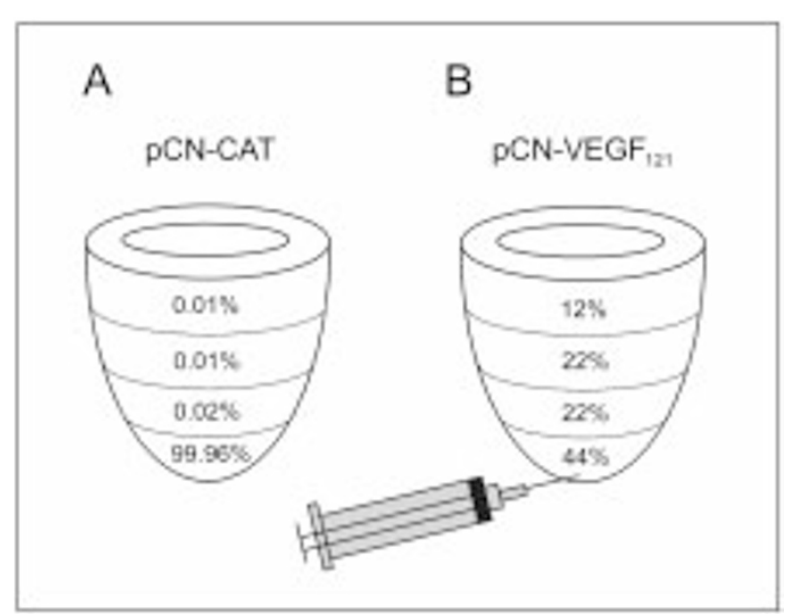

Figure 4. Spatial distribution of expression of (A) CAT protein $(30 \mu \mathrm{g} \mathrm{pCN}$ $\mathrm{CAT})$ and (B) VEGF ${ }_{121}$ protein $\left(250 \mu \mathrm{g}\right.$ pCN-VEGF $\left.{ }_{121}\right)$, following a single injection into the rat heart. Plasmid DNA was injected into the apex of the individual heart. Three days (CAT), or two days $\left(\mathrm{VEGF}_{121}\right)$ after injection of each construct, rats were sacrificed and hearts were excised. The hearts were divided into four sections from apex to base. Using ELISA, each section was then assayed individually for the presence of protein. Values are given as the mean of three rats, expressed as a percentage of total protein content of the entire heart.

$22 \%$ in the middle sections, and $12 \%$ in the basal section, reflecting secretion and diffusion of the $\mathrm{VEGF}_{121}$ protein.

\section{Discussion}

Both the development of a potent vector to deliver the VEGF gene, and an understanding of the kinetics and distribution of VEGF gene expression, are potentially of profound importance in angiogenic gene therapy. Two observations result from this study. Firstly, we have demonstrated that a vector with the HCMV IE promoter/ enhancer induces more potent gene expression in the myocardium than do other vectors with viral or cellular promoters. This finding is noteworthy, given the low efficiency of transfection by naked DNA. Secondly, using the above vector, we have defined the behavior of the therapeutic gene, VEGF ${ }_{121}$, injected into the rat heart, with respect to the dose-response effects, and the temporal and spatial distribution of gene expression, all of which are quite different from those of the reporter gene (CAT). Our results, therefore, provide useful information applicable to angiogenic gene therapy in patients with coronary artery disease.

Gene therapy has been proposed or investigated for a number of cardiac diseases, including the treatment of congestive heart failure and therapeutic angiogenesis (Yla-Herttuala et al., 2000). Preliminary results utilizing this approach as the sole therapy for patients with chronic myocardial ischemia suggest that direct injection of VEGF as naked DNA into cardiac myocytes may improve collateral blood flow and reduce the frequency of, and threshold for, myocardial ischemia (Losordo et al., 1998; Symes et al., 1999). Therapeutic angiogenesis is an innovative approach to the treatment of ischemic diseases, whereby the administration of the VEGF gene facilitates the "biological revascularization" of obstructed vascular segments, and the reperfusion of ischemic tissues (Rosengart et al., 1999). Moreover, it has been suggested that in certain cases of heart failure, the angiographically occult intramural coronary vasculature consists the locus of the disease as well as the cure (Isner and Losordo, 1999). In this case angiogenic gene therapy may have therapeutic implications in the treatment of heart failure.

Naked DNA is probably the safest and the most convenient form for the delivery of gene vectors (Kay et al., 1997). Moreover, since the myocardium takes up DNA more efficiently than other tissue types, gene injection into the rat heart is quite efficient, and results in levels of gene expression up to 50-fold higher than similar experiments in skeletal muscles (Lin et al., 1990; Kitsis et al., 1991; Buttrick et al., 1992). However, gene expression resulting from direct naked DNA injection into the myocardium is lower, by orders of magnitude, than that seen with adenovirus infection of the myocardium (Kass-Eisler and Leinwand, 1997). Therefore, the best way of making naked DNA gene therapy affordable is to use an expression system that will drive the highest possible level of therapeutic protein expression.

To develop a high efficiency expression plasmid for naked DNA gene therapy, the relative strengths of five different promoters were determined: HCMV IE pro-moter/ enhancer, HCMV IE promoter, RSV LTR, EF $1-\alpha$, and $\beta$ actin, all fused to the CAT reporter gene. The $\mathrm{pCN}$ vector with the HCMV IE promoter/enhancer was app-roximately sevenfold more active than vectors carrying other viral and cellular promoters. In previous reports, viral promoters such as HCMV IE and RSV, and tissue-specific promoters such as $\alpha-\mathrm{MHC}$, were tested in the myocardium (Lin et al., 1990; Kitsis et al., 1991; Buttrick et al., 1992; von Harsdorf et al., 1993; Li et al., 1997). It was reported that viral promoters were more potent than tissue-specific promoters in the heart (Buttrick et al., 1992; von Harsdorf et al., 1993). The adult-type EF- $1 \alpha$ protein is one of the most abundant proteins in eukaryotic cells (Slobin, 1980). Even though the promoter of the human EF-1 $\alpha$ gene has well-recognized, strong promoter activity in various types of cells (Wakabayashi-lto and Nagata, 1994), pCN was more potent than $p E F$ in the myocardium. However, we cannot rule out the possibility that cellular promoters ( $p E F$ or pAct) induce longer-term gene expression than viral promoters.

The plasmid pCN was constructed to contain, not only the full length IE promoter of HCMV, but also its entire $5^{\prime}$ untranslated region, comprising all of exon 1 and intron 1, and a part of exon 2. In addition, our vector was designed in such a way that the start codon of the 
inserted gene coincides with the ATG codon of the original IE gene of HCMV, which is not the case in many other HCMV promoter-based expression vectors (Petitclerc et al., 1995). This strategy is based on a variety of data suggesting that IE genes, such as IE1 and IE2, are expressed at very high levels during HCMV infection, and that such high levels of gene expression are determined not only by the promoter, but also by the untranslated leader sequence of the coding region (Chapman et al., 1991; Simari et al., 1998).

We have shown that the expression of injected CAT constructs exhibits features of saturation kinetics at doses above $10 \mu \mathrm{g}$, and even results in decreased levels of expression at higher doses. To some extent, these phenomena of saturation and decreased gene expression have been demonstrated before, when very high doses of CAT-coding naked DNA were injected into the canine myocardium (von Harsdorf et al., 1993), or when gene expression was enhanced by electroporation of the luciferase gene into rat liver (Heller et al., 1996).

The temporal characteristics of $\mathrm{pCN}$-CAT expression presented here are consistent with previous reports of gene injection in mouse, rat, and dog hearts (Buttrick et al., 1992; von Harsdorf et al., 1993; Li et al., 1997). This implies that, even though $\mathrm{pCN}$ induces higher levels of gene expression, the temporal pattern of gene expression is no different from that found with other viral promoters used previously. Gene expression after injection of plasmid DNA is generally stable over time, which is one of the advantages of this method when compared to the more transient gene expression following recombinant adenovirus injection (Kass-Eisler and Leinwand, 1997). However, this pattern of expression, assayed at the protein level, is likely to overestimate the duration of expression of the injected DNA, because in most cell types the CAT protein has a long half-life of more than $50 \mathrm{~h}$ (Thomson et al., 1991). Therefore, the pattern of CAT gene expression shown in Figure 2B not only reflects the activity of the driving promoter, but also reflects the half-life of the expressed protein as well.

Despite the clinical use of VEGF gene transfer as naked DNA, there are no published reports of doseresponse effects, or of the temporal or spatial characteristics of VEGF expression following DNA injections into the heart. Since assays for a reporter gene do not necessarily reflect the behavior of the therapeutic gene, we wished to address whether the expression of VEGF and CAT exhibited similar behaviors. In contrast to the patterns of reporter gene expression, which were doselimited, very stable over four weeks, and restricted to a limited area of the left ventricle, the kinetics of VEGF ${ }_{121}$ expression were quite different. The level of protein extracted from hearts was lower by orders of magnitude than that of CAT protein. While CAT gene expression showed a decrease of protein with higher doses of plasmid, there was a dose-response relationship be- tween the level of VEGF gene expression and the quantity of plasmid DNA injected for doses between 10 and $200 \mu \mathrm{g}$ per injection site, indicating that VEGF protein has no deleterious effect on gene expression. We suggest that this is the case, either because the level of VEGF is low, or because VEGF is a eukaryotic protein whereas CAT protein is of bacterial origin. Furthermore, VEGF exhibited an earlier peak of protein expression than CAT, and a rather rapid decline of gene expression over time, reflecting the short half-life of the VEGF $_{121}$ protein. However, expression of VEGF ${ }_{121}$ was readily detected by ELISA in all hearts injected with 100 $\mu \mathrm{g}$ of DNA. Expression of the exogenous gene lasted a surprisingly long time, as significant levels of VEGF were detectable even 14 days after a single injection. Since the half-life of VEGF is known to be only a few minutes (Ferrara et al., 1992), our DNA must exist in a relatively stable form.

The spatial distribution of CAT gene expression showed a pattern similar to that found in previous studies (Lin et al., 1990; Buttrick et al., 1992). The histological distribution of cell transfection has been addressed in several reports, either by analysis of expression in different areas around the injection site (Buttrick et al., 1992), or by the use of constructs containing the lacZ gene (Lin et al., 1990). Apparently, only cells in the immediate vicinity of the needle tract are transfected. Therefore, VEGF naked DNA could only transfect the apical portion of the heart surrounding the injection site. However, VEGF could be detected in other parts of the heart, reflecting the secretory and diffusible nature of the $\mathrm{VEGF}_{121}$ protein. This finding has clinical implications, because it means that the injection sites of VEGF DNA need not exactly match the ischemic lesions.

In conclusion, in angiogenic gene therapy for the patients with coronary artery diseases, plasmid vectors with the HCMV IE promoter/enhancer will provide clear advantages over other previously developed plasmids. Furthermore, knowledge of the kinetics and distribution of VEGF expression will also prove to be useful in this context.

\section{Acknowledgements}

The authors thank Jeong-Eun Huh and Sun-Jin Park for their technical assistance. This work has been supported by the National Research Laboratory Grants from the Korea Institute of Science and Technology Evaluation and Planning, and Korean Ministry of Health and Welfare (01PJ1-PG1-01CH06-0003), and Science Research Center Grants from Korea Science and Engineering Foundation to DK Kim.

\section{References}

Buttrick PM, Kass A, Kitsis RN, Kaplan ML, Leinwand LA. 
Behavior of genes directly injected into the rat heart in vivo. Circ Res 1992;70:193-8

Carmeliet P, Ng YS, Nuyens D, Theilmeier G, Brusselmans K, Cornelissen I, Ehler E, Kakkar VV, Stalmans I, Mattot V, Perriard JC, Dewerchin M, Flameng W, Nagy A, Lupu F, Moons L, Collen D, D'Amore PA, Shima DT. Impaired myocardial angiogenesis and ischemic cardiomyopathy in mice lacking the vascular endothelial growth factor isoforms VEGF164 and VEGF188. Nat Med 1999;5:495-502

Chapman BS, Thayer RM, Vincent KA, Haigwood NL. Effect of intron A from human cytomegalovirus (Towne) immediateearly gene on heterologous expression in mammalian cells. Nucleic Acids Res 1991;19:3979-86

Darren CW, Tana R, Manjunatha Kinia, Seetharama DS, Joisb Derrick KF, Lima. Lixia Xina and Ruowen Gea. A small peptide derived from Flt-1 (VEGFR-1) functions as an angiogenic inhibitor. FEBS Lett 2001;494:150-6

Ferrara N, Houck K, Jakeman L, Leung DW. Molecular and biological properties of the vascular endothelial growth factor family of proteins. Endocr Rev 1992;13:18-32

Heller R, Jaroszeski M, Atkin A, Moradpour D, Gilbert R, Wands J, Nicolau C. In vivo gene electroinjection and expression in rat liver. FEBS Lett 1996;389:225-8

Isner JM, Losordo DW. Therapeutic angiogenesis for heart failure. Nat Med 1999;5:491-2

Kass-Eisler A, Leinwand LA. DNA- and adenovirus-mediated gene transfer into cardiac muscle. Methods Cell Biol 1997;52: 423-37

Kay MA, Liu D, Hoogerbrugge PM. Gene therapy. Proc Natl Acad Sci USA 1997;94:12744-6

Kitsis RN, Buttrick PM, McNally EM, Kaplan ML, Leinwand LA. Hormonal modulation of a gene injected into rat heart in vivo. Proc Natl Acad Sci USA 1991;88:4138-42

Lee YJ, Park EJ, Yu SS, Kim DK, Kim S. Improved expression of vascular endothelial growth factor by naked DNA in mouse skeletal muscles: implication for gene therapy of ischemic diseases. Biochem Biophys Res Commun 2000;272:230-5

Li K, Welikson RE, Vikstrom KL, Leinwand LA. Direct gene transfer into the mouse heart. J Mol Cell Cardiol 1997;29: 1499-504

Lin H, Parmacek MS, Morle G, Bolling S, Leiden JM. Expression of recombinant genes in myocardium in vivo after direct injection of DNA. Circulation 1990;82:2217-21

Losordo DW, Vale PR, Symes JF, Dunnington $\mathrm{CH}$, Esakof DD, Maysky M, Ashare AB, Lathi K, Isner JM. Gene therapy for myocardial angiogenesis: initial clinical results with direct myocardial injection of phVEGF165 as sole therapy for myocardial ischemia. Circulation 1998;98:2800-4

Neufeld G, Cohen T, Gengrinovitch S, Poltorak Z. Vascular endothelial growth factor (VEGF) and its receptors. FASEB J 1999;13:9-22

Park JE, Keller GA, Ferrara N. The vascular endothelial growth factor (VEGF) isoforms: differential deposition into the subepithelial extracellular matrix and bioactivity of extracellular matrix-bound VEGF. Mol Biol Cell 1993;4:1317-26

Petitclerc D, Attal J, Theron MC, Bearzotti M, Bolifraud P, Kann G, Stinnakre MG, Pointu H, Puissant C, Houdebine LM. The effect of various introns and transcription terminators on the efficiency of expression vectors in various cultured cell lines and in the mammary gland of transgenic mice. J Biotechnol 1995;40:169-78

Rosengart TK, Patel SR, Crystal RG. Therapeutic angiogenesis: protein and gene therapy delivery strategies. J Cardiovasc Risk 1999;6:29-40

Simari RD, Yang Z, Ling X, Stephan D, Perkins ND, Nabel GJ, Nabel EG. Requirements for enhanced transgene expression by untranslated sequences from the human cytomegalovirus immediate-early gene. Mol Med 1998;4:700-6

Slobin LI. The role of eucaryotic factor Tu in protein synthesis. The measurement of the elongation factor Tu content of rabbit reticulocytes and other mammalian cells by a sensitive radioimmunoassay. Eur J Biochem 1980;110:555-63

Symes JF, Losordo DW, Vale PR, Lathi KG, Esakof DD, Mayskiy M, Isner JM. Gene therapy with vascular endothelial growth factor for inoperable coronary artery disease. Ann Thorac Surg 1999;68:830-7

Thomson JF, Hayes LS, Lloyd DB. Modulation of firefly luciferase, stability and impact on studies of gene regulation. Gene 1991;103:171-7

Verma IM, Somia N. Gene therapy - promises, problems, and prospects. Nature 1997;389:239-42

von Harsdorf R, Schott RJ, Shen YT, Vatner SF, Mahdavi V, Nadal-Ginard B. Gene injection into canine myocardium as a useful model for studying gene expression in the heart of large mammals. Circ Res 1993;72:688-95

Wakabayashi-Ito N, Nagata S. Characterization of the regulatory elements in the promoter of the human elongation factor-1 alpha gene. J Biol Chem 1994;269:29831-7

Yla-Herttuala S, Martin JF. Cardiovascular gene therapy. Lancet 2000;355:213-22 